\title{
Field Potentials Recording in the Brain tissue \\ as a New Criterion for Determination \\ of Glialtumors Boundaries
}

DOI: $10,17691 / \mathrm{stm} 2018.10 .3 .4$

Received May 8, 2018

M.A. Mishchenko, PhD, Researcher, Department of Theory of Oscillations and Automatic Control,

Faculty of Radiophysics 1 ;

A.V. Lebedeva, PhD, Researcher, Functional Imaging Laboratory, Department of Basic and Applied Research;

Assistant, Department of Neurotechnologies, Institute of Biology and Biomedicine";

T.A. Mishchenko, PhD, Senior Researcher, Laboratory for Neuroprotection Methods Development,

Center for Translational Technologies ${ }^{1}$; Senior Researcher, Molecular and Cell Technologies Department,

Central Scientific Research Laboratory2;

K.S. Yashin, MD, Junior Researcher, Laboratory of Super-Resolution Microscopy and Gene Technologies,

Institute of Biomedical Technologies2; Neurosurgeon, Institute of Traumatology and Orthopedics; ;

L.S. Lepekhina, Master, Department of Neurotechnologies, Institute of Biology and Biomedicine";

K.A. Astafyeva, Junior Researcher, Department of Physico-Chemical Researches,

Central Scientific Research Laboratory;

I.P. Ivanova, DSc, Head of the Department of Physico-Chemical Researches,

Central Scientific Research Laboratory;

M.V. Vedunova, DSc, Leading Researcher, Institute of Biology and Biomedicine';

Director of Institute of Biology and Biomedicine';

I.A. Medyanik, MD, DSc, Leading Researcher, Microneurosurgery Group, Institute of Traumatology and Orthopedics';

V.B. Kazantsev, DSc, Vice-Rector for Research ${ }^{1}$; Head of the Department of Neurotechnologies, Institute of Biology and Biomedicine ${ }^{1}$

${ }^{1}$ Lobachevsky State University of Nizhni Novgorod, 23 Prospekt Gagarina, Nizhny Novgorod, 603950, Russia;

2Privolzhsky Research Medical University, 10/1 Minin and Pozharsky Square, Nizhny Novgorod, 603005, Russia

The aim of the study was to evaluate the electrophysiological activities of tumor and peritumoral tissues in an experimental glioblastoma model and rationalize their use for determining the tumor boundaries.

Materials and Methods. Following methods were used in this study: extracellular electrophysiological activity (field postsynaptic potentials) registration; astrocytic glutamate currents patch-clamp registration; magneto-resonant imaging; surgical techniques in vivo. The experiments were performed using cell cultures (primary murine astrocyte culture and constant cell line cultures of rat glioma cells 2211), acute murine hippocampal slices, and rats with transplanted malignant glioma 101.8.

Results. A number of electrophysiological parameters of neurons and glial cells were evaluated using cell cultures, acute hippocampal slices, and the rat brain as a whole. Field postsynaptic potentials in the brain tissue differed between the non-injured areas and the zone of glioma development. No field potentials detected in the tumoral area, indicating the lack of excitability in the tumor cells.

Conclusion. Field potentials recorded in the brain tissue in vivo can be used as a novel criterion for determining the glial brain tumors boundaries.

Key words: glioma; astrocyte; postsynaptic field potential; tumor boundary; intraoperative diagnosis.

\section{Introduction}

Diagnosis and treatment of brain gliomas remains one of the most challenging areas of neurooncology. The average time of survival in patients with glioma is 10-24 months; in rare cases, it can reach 5 years [13]. The currently used therapy of malignant gliomas involves a number of methods, including microsurgery for tumor removal, radiation, and chemotherapy, sometimes in combination with photodynamic therapy and immunotherapy [4-6].

Surgical resection is the core of all treatment regimens, as it allows the surgeon to remove a large volume of tumor tissue, reduce intracranial hypertension and neurological deficit, and post-operatively determine the tumor morphology and phenotype to address the issue of further treatment. A major problem of the surgical approach is keeping the balance between the maximal

Corresponding author: Mikhail A. Mishchenko, e-mail: mischenko@neuro.nnov.ru 
tumor removal and the minimal damage to the vital brain structures adjacent to the tumor. It is commonly agreed that the total removal of tumor cells by surgery is not practically feasible because of the invasive nature of tumor growth; the tumor can penetrate the surrounding tissues up to the radius of several centimeters where it continues to grow [2, 7-11]. In these circumstances, an accurate diagnosis of the tumor, and especially determination of its boundaries is crucially important.

To approach this problem and determine the boundaries of glial brain tumors, one has to know about the differences between normal and pathological glial cells, and about their interaction on the interface between the tumor and the intact tissue. Thus, differences in the excitatory amino acid transporters between glioma cells and normal glia cells have been reported [12]. Physiologically, astrocyte transporters are essential for normal synaptic transmission: they provide a rapid removal of glutamate from the synaptic cleft and thus prevent glutamate excess and excitotoxicity. The development of glial tumors disrupts the function of these transports, which negatively impacts the glial cell metabolism and, consequently, interferes with synaptic transmission.

The determination of glial tumor boundaries is a novel approach to the diagnosis of glioma; the technique is based on the brain cells response to electrical stimulation, which constitutes the essence of the normal neuron functioning. Contrary to that, glial tumor cells are electrically inexcitable. This approach is unique for neurosurgery, since, unlike other existing methods, it is based on a functional and not morphological analysis. Such information is vital for neurosurgeons as they need more tools to precisely determine the tumor boundaries during the operation to avoid intraoperative brain damage.

The aim of the study was to evaluate the electrophysiological features of malignant brain tumors and peritumoral areas by recording their field potentials appearing in response to electrical stimulation.

\section{Materials and Methods}

An immortalized cell culture of rat glioma cells 2211 and primary astrocyte cultures obtained from C57BL/6 neonatal mice $(P=2)$ were used as the material for the in vitro studies.

In vivo experiments were carried out using mature male Wistar rats with transplanted malignant glioma (glioblastoma) 101.8 obtained from the Research Institute of Human Morphology (Moscow, Russia) [13]. The age of rats at the time of tumor transplantation was 2.5 months. The experiments were carried out 10-12 days after the glioma transplantation.

The basic rules for the maintenance and care of experimental animals were in accordance with the Rules for the Work using Experimental Animals (Russia, 2010) and the International Guiding Principles for Biomedical
Research Involving Animals (CIOMS and ICLAS, 2012), while ethical principles established by the European Convention for the Protection of Vertebrate Animals used for Experimental and other Scientific Purposes (Strasbourg, 2006) were strictly observed. The approval for conducting the animal studies was obtained from the Bioethics Committee of the National Research Lobachevsky State University of Nizhni Novgorod.

Constant cell line culture. Constant cell line cultures of rat glioma cells 2211 were obtained from the Russian cell cultures collection of vertebrates at the Institute of Cytology of the Russian Academy of Science (St. Petersburg, Russia). Cells were cultured in the Eagle's Minimal Essential Medium with $0.32 \mathrm{mg} / \mathrm{ml}$ glutamine and $10 \%$ fetal bovine serum (all the above reagents from PanEco, Russia). At the end of the exponential growth, the cells were removed from the cultural flask with versine $(0.02 \%)$ :trypsin $(0.25 \%)$ at $3: 1$ and then reseeded with the multiplicity of sieving $1: 10$. Experiments were carried out after the third passage.

Primary astrocyte cultures. Primary astrocyte cultures were obtained from the cerebral cortex of newborn mice $(P=2)$. The surgically extracted brain tissue underwent mechanical grinding and enzymatic dissociation with a $0.25 \%$ trypsin solution (Invitrogen, USA). After centrifugation (1000 rpm, $3 \mathrm{~min}$ ), the cell suspension was placed on coverslips $(18 \times 18 \mathrm{~mm})$ pretreated with the positively charged hydrophilic polyethyleneimine (Sigma, USA) for a better cellssubstrate attachment. The cells were then cultured in the Dulbecco's Modified Eagle Medium with the addition of $0.32 \mathrm{mg} / \mathrm{ml}$ glutamine, $10 \%$ fetal bovine serum and $1 \mathrm{mM}$ pyruvic acid (Sigma, USA) during 30 days.

The primary cultures and the constant cell line cultures were maintained in a MCO-18AIC incubator (Sanyo, Japan) at $35.5^{\circ} \mathrm{C}$ and $5 \% \mathrm{CO}_{2}$. The cells of both types were examined for their morphology using widefield light microscopy and an Axio Observer.A1 inverted fluorescence microscope (Carl Zeiss, Germany).

Anesthesia. Before the procedure of tumor transplantation (and also prior to MRI), each animal was anesthetized by intraperitoneal Zoletil 100 injection (Virbac Sante Animale, France) at concentration of $125 \mathrm{mg} / \mathrm{kg}$. The degree of sedation was tested by the absence of the pain reflex (limb tweezing response). Further, the animal was intramuscularly injected with a $2 \%$ solution of analgesic and myorelaxant Romethar (Interchemie, The Netherlands) at $0.2 \mathrm{ml} / \mathrm{kg}$ weight.

Tumor transplantation and timing of the in vivo experiment. Tumor cells suspended in Hank's solution at a concentration of $10^{5}-10^{6} \mathrm{cell} / \mathrm{ml}$ were injected into the right parietal region (2 $\mathrm{mm}$ lateral of the sagittal suture and $2 \mathrm{~mm}$ posterior of the coronal suture). In this location, craniotomy (2 $\mathrm{mm}$ in diameter) was performed using a dental drill. Then the dura matter was opened and tumor cells injected into the brain at 2-4 $\mathrm{mm}$ depth using a trocar.

The first symptoms of a neoplastic process 
manifested clinically by the lack of mobility, appetite, and self-cleaning appeared 5-7 days after transplantation.

The clinical picture of glioblastoma was developed by days 9 to 11 after cell transplantation. The manifestations depended on the nature of tumor growth. Even with a limited growth in the parietal zone, but with a spread into the cerebral cortex and the brain ventricles, focal abnormalities and hemiparesis were observed in 65$80 \%$ of rats.

On 11-13 days after transplantation, the tumor reached a size of $\sim 1.5-2.2 \mathrm{~cm}^{3}$, which led to a rapid lethal outcome. The optimal period to perform electrophysiological recordings in the experiment was 10-12 days after the transplantation when the tumor became mature and reached its maximal size. To verify the size and location of the tumor we used MRI.

Magnetic resonance imaging. The anesthetized animal was put into a small cage and then placed in a superconducting magnetic resonance tomograph of the tunnel type Agilent DD2 NMR 400WB (Agilent Technologies, USA) with an operating frequency of $400 \mathrm{MHz}$ and a static magnetic field of $9.4 \mathrm{~T}$.

To obtain the structural T2-weighted images, the FSEMS (fast spin echo multi-slice) pulse sequence was used. The cycle time is $3000 \mathrm{~ms}$, the echo time is from $40 \mathrm{~ms}$, the size of the matrix is $256 \times 192$, the number of slices is 10 , the slice thickness is $1 \mathrm{~mm}$, and the field of view is $40 \times 40 \mathrm{~mm}$.

Extracellular recording of electrophysiological activity. The animal was anesthetized with $5 \%$ isoflurane inhalation. Craniotomy was performed using a drill Unibur-MK (Sapphire, Russia) from the upper sagittal sinus to the upper temporal line, from the upper jaw to the transverse sinus. To avoid heating of the dura mater, the bur was irrigated with cold saline every $10 \mathrm{~s}$.

The electrophysiological activity (field excitatory postsynaptic potentials, fEPSP) were recorded using an Olympus BX51WI light microscope (Olympus, Japan) equipped with automated manipulators, recording and stimulating electrodes, and an amplifier (MultiClamp 700B, Axon Instruments, USA). The stimulating electrode was a bipolar steel electrode (FHC Inc., USA) placed at different areas of the trepanation window, depending on the task. The recording electrode was a microelectrode with a resistance of 4-7 $\mathrm{M} \Omega$ produced from a glass capillary (Harvard Part No.300053) using a P-97 puller (Sutter Instruments, USA). For the fEPSP recording the electrode was filled with an intracellular solution composed of: $119 \mathrm{mM} \mathrm{NaCl}$; $2.5 \mathrm{mM} \mathrm{KCl} ; 1.3 \mathrm{mM} \mathrm{MgSO}_{4} ; 1 \mathrm{mM} \mathrm{NaH} \mathrm{PO}_{4} ; 26.2 \mathrm{mM}$ $\mathrm{NaHCO}_{3} ; 2 \mathrm{mM} \mathrm{CaCl}_{2}$; and $10 \mathrm{mM}$ D-glucose $(\mathrm{pH} 7.4$, osmolarity - $298 \mathrm{mOsm}$ ). The field potentials were recorded in different areas of the trepanation window in the zero current mode $(l=0)$ depending on the task.

The obtained electrophysiological data were analyzed using the following software: WinWCP 4.7 (http://winscp. net), Clampfit (Axon Instruments Inc., USA), and Origin Pro 2016 (OriginLab, USA).

\section{Results}

At the first stage, we studied the glutamate transporter currents in glial cells using acute hippocampal slices and cultured glioma cells. Glutamate currents occur during the synaptic transmission; these currents are viewed as a major contributor into the functional activity of astrocytes in the brain [14-15]. Excitation of the astrocyte transporter current was triggered by a local application of glutamate through a patch pipette. In this experiment, we found no difference in the glutamate transport current kinetics between astrocytes in the acute hippocampal slices and cultured glioma cells (Figure 1).

Despite the significant metabolic changes that occur during cell malignant transformation, there was no difference in changes in one of the main electrophysiological parameters of astrocytes, which makes it impossible to use this parameter as a criterion of the glial tumors boundaries.

Therefore, at the next stage, we tested field potentials as a possible diagnostic parameter. Field potentials represent the total electric potential that arises in a group

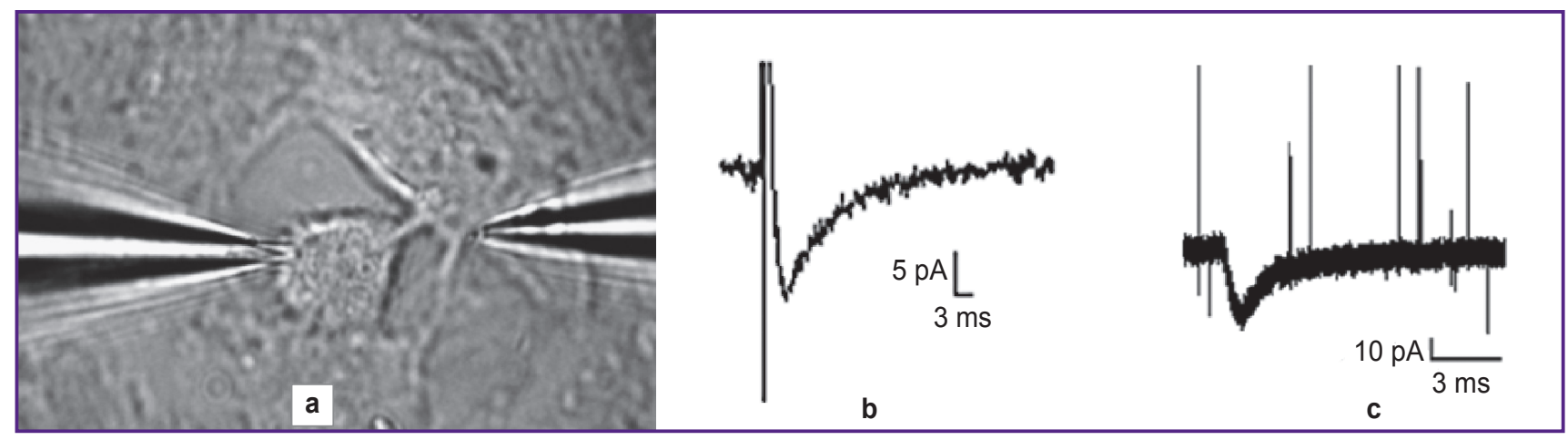

Figure 1. Representative electrophysiological recordings of transporter currents in astrocyte:

(a) glutamate-induced excitation; (b) acute hippocampal slices; (c) cultured glioma cells 


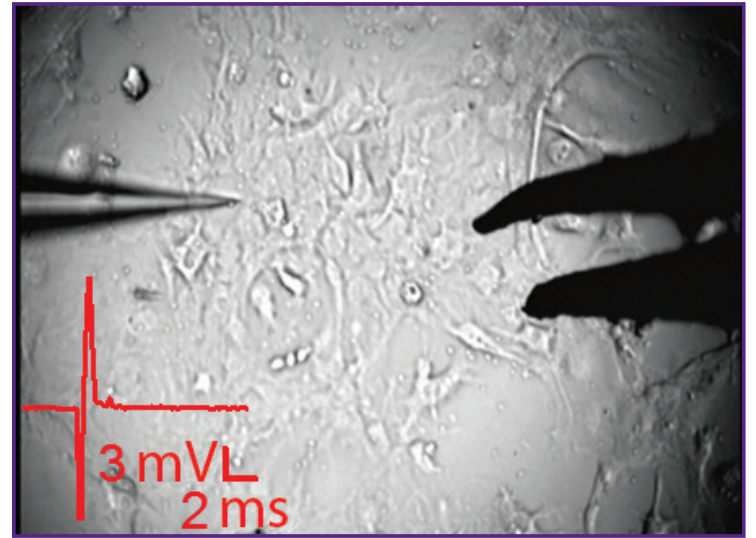

Figure 2. Field potentials in astrocyte culture

of neurons (population spike) or a group of excitatory synapses (field excitatory postsynaptic potential, fEPSP) activated by electrical stimulation of neighboring neuronal dendrites.

The field potential is characterized by the amplitude and the slope reflecting the number of activated neurons and dendrites. It is known that astrocytes are electrically non-excitable and they do not generate action potentials [16]. We assumed though that upon oncotransformation, astrocytes could acquire the ability to generate action potentials, for example, fEPSP. To test this hypothesis, we attempted to measure field potentials in cultured astrocytes. No measurable fEPSP could be detected in the astrocyte culture in response to an electrical stimulus (Figure 2).

The next step of the study was an in vivo experimentation on Wistar rats with transplanted glioma 101.8. We verified the size and location of glioma in the brain using MRI (Figure 3). Then, fEPSP of various brain areas were registered in those rats with glioma 101.8. In these experiments, we placed the stimulating and recording electrodes at different locations keeping the same distance of $4 \mathrm{~mm}$ between them. Using this setup, we were able to identify the areas that gave a physiological response to electrical stimulation (intact tissue) and the areas with no response (glioma). Differences in the fEPSP between the normal and malignant brain tissues were detected (Figure 4).

When the response comes from the tumor zone or from the immediate tumor vicinity (the peritumoral zone), the signal amplitude is lower than normal (Figure 4 (a), (b)), which may be due to the damaged signalconducting myelin fibers or to destroyed brain cortex.

The extracellular electrical stimulation of the nervous tissue (Figure 4 (a), (b), (c)) is able to affect both nearby cells and rather remote ones, since the electric field generated by the stimulating pulse propagates through the intercellular medium or through the partially preserved nerve fibers. Although during its propagation this electric field attenuates, at relatively high amplitudes it can still create a local depolarization of neuron membranes, which can trigger the generation of action potentials. This may be the mechanism underlying the rise of the fEPSP (up to $1 \mathrm{mV}$ ) on the electrode located in the intact tissue when the stimulating electrode is placed in the area of glioma development (see Figure 4 (c)).

Normally, the amplitude of a fEPSP correlates with the amplitude of a stimulating signal; accordingly, we noted an increase in the response with an increase in the stimulus when both electrodes were located in the intact brain tissue (Figure 5). Contrary to that, no response was detected under the similar stimulation when both the stimulating and recording electrodes were placed in the tumor zone (Figure 6).

At the next stage of the study, we measured the electrophysiological parameters in the brain area where the tumor had been removed, i.e. under the conditions simulating the neurosurgical procedure of tumor removal. Since glial tumors grow along the white matter fibers, our experimentation focused on recording the fEPSP in the subcortical structures of the brain. With the stimulation electrode in the tumor "bed", we were able to detect a low level fEPSP with the amplitude much smaller than that recorded in the intact cortical tissue. The result indicates the presence of excitable and responsive cells in the tumor "bed" after surgical removal of the tumor (Figure 7).
Figure 3. Representative brain MRI images of Wistar rats:

(a) rat from the control group with no brain tumor; (b) rat with a brain tumor (day 11 after tumor inoculation)
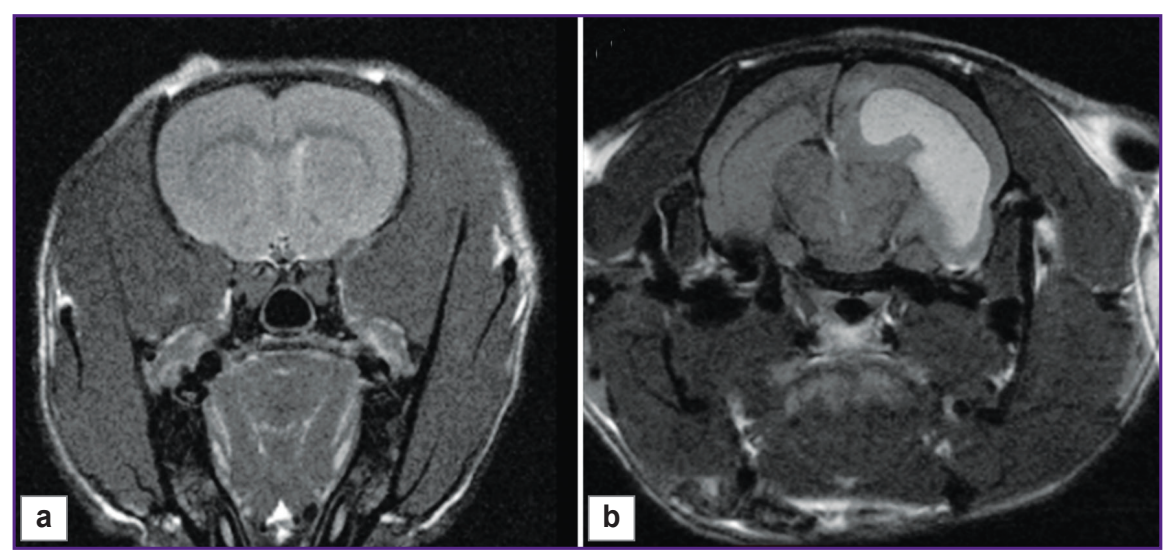


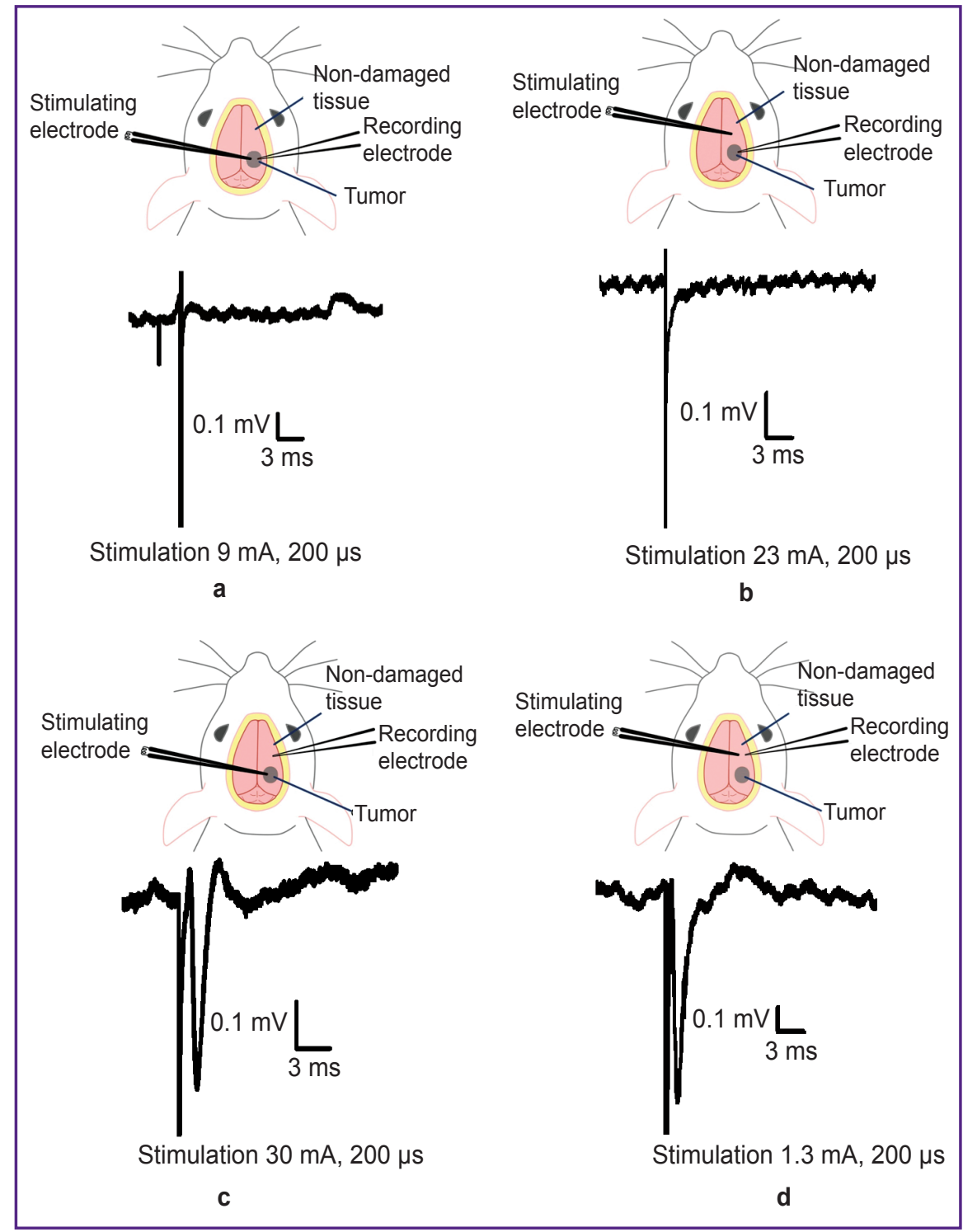

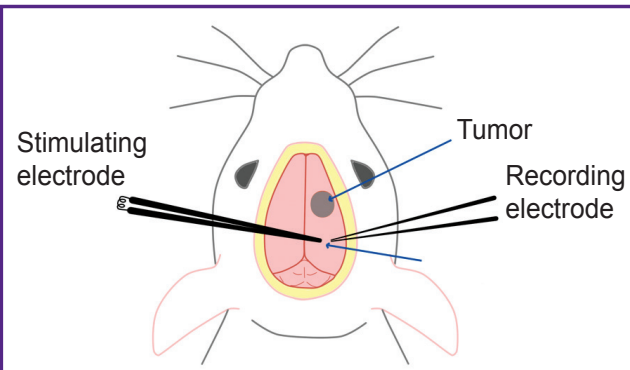

a

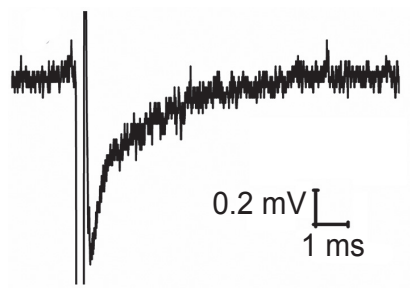

Stimulation $1 \mathrm{~mA}, 200 \mu \mathrm{s}$

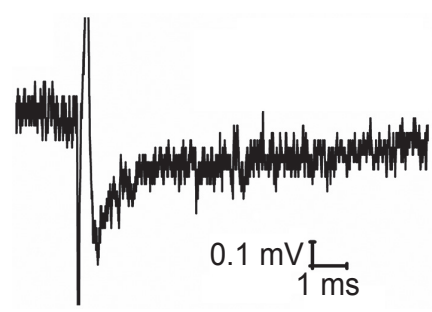

Stimulation $300 \mu \mathrm{A}, 200 \mu \mathrm{s}$

b

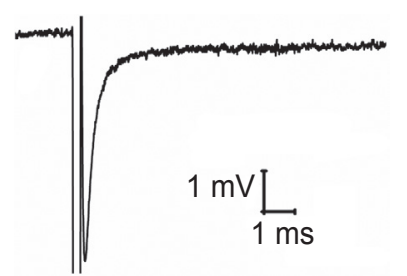

Stimulation $10 \mathrm{~mA}, 200 \mu \mathrm{s}$ d
Figure 4. Layout of stimulating and recording electrodes in the rat brain and appropriate field potentials recordings:

(a) both electrodes are located in the tumor; (b) the recording electrode is located in the tumor, and the stimulating one - in the non-damaged tissue; (c) the stimulating electrode is located in the tumor, and the recording one - in the non-damaged tissue; (d) both electrodes are located in the non-damaged tissue
Figure 5. fEPSP recording in the non-injured area of the brain:

(a) electrode layout; (b) fEPSP stimulated by $300 \mu \mathrm{A}$ current, $0.2 \mathrm{mV}$ amplitude response; (c) fEPSP stimulated by $1 \mathrm{~mA}$ current, $1.2 \mathrm{mV}$ amplitude response; (d) fEPSP stimulated by $10 \mathrm{~mA}$ current, $5 \mathrm{mV}$ amplitude response 
Figure 6. Representative example of fEPSP recording in the inoculated glioblastoma 101.8:

(a) electrode layout; (b) no response to $300 \mu \mathrm{A}$ stimulus; (c) no response to $1 \mathrm{~mA}$ stimulus; (d) no response to $10 \mathrm{~mA}$ stimulus

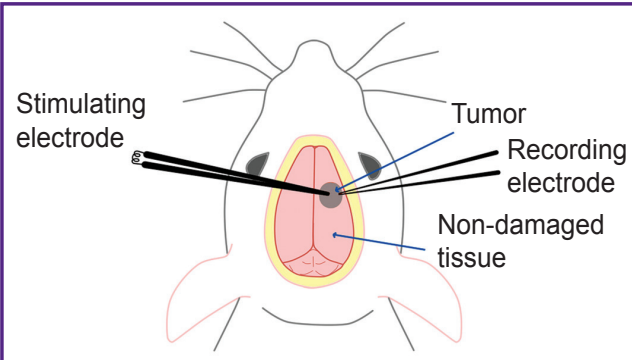

a

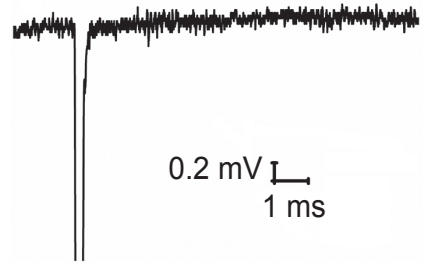

Stimulation $1 \mathrm{~mA}, 200 \mu \mathrm{s}$

C

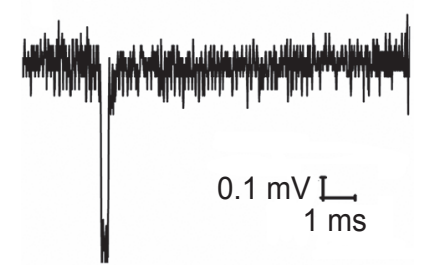

Stimulation $300 \mu \mathrm{A}, 200 \mu \mathrm{s}$

b



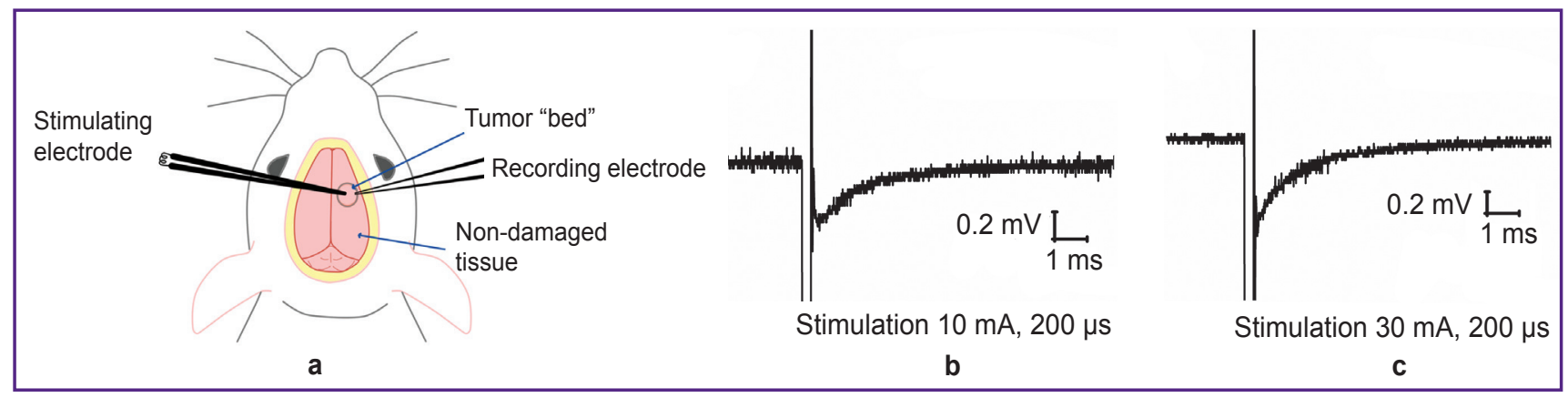

Figure 7. Representative example of fEPSP recording in the tumor bed after removal of glioblastoma 101.8:

(a) electrode layout; (b) response to $10 \mathrm{~mA}$ stimulus, $0.2 \mathrm{mV}$ amplitude response; (c) response to $30 \mathrm{~mA}$ stimulus, $0.5 \mathrm{mV}$ amplitude response

\section{Discussion}

As a result of the present studies, it was found that the electrophysiological activity - as measured by electrically stimulated fEPSP - significantly differed between the intact and oncotransformed brain tissues. Thus, no response to electrical stimulation was detected in the oncotransformed tissue, while the intact tissue produced a field potential with the amplitude that increased with an increasing stimulating signal. In addition, field potentials also arose in response to the tumor "bed" stimulation in the subcortical structures of the brain. The present results suggest that the differences in the fEPSP between normal and oncotransformed brain tissues can be used as a diagnostic criterion for intraoperative determination of the boundaries of glial brain tumors. Our experimentation showed that the location of the recording and stimulating electrodes was of key importance. In the rat brains with transplanted glioma 101.8, the generation of field potentials was tested using four possible electrode locations. In our setup, the stimulating and recording electrodes were placed either in the same zone or in two different zones (intact tissue and/or glioma). When the recording electrode is located in the intact tissue, the field potential responsive to an increasing stimulus arises regardless of where the stimulating electrode is placed. If the recording electrode is located in the area of tumor development, which has no electrically excitable nerve cells, no field potentials arise. In the "bed" of the removed tumor situated in the subcortical structures, field potentials are generated in the neighboring nerve fibers or their remains. In these cases, the amplitudes of the recorded signals are lower than those from the cortical areas of normal brains. Yet contrary to the areas of tumor development, the fEPSP from the tumor "bed" are detectable. This may indicate the existence of functionally active nerve cells able to form new dendrites in the brain after surgical tumor removal. The main factors limiting the radical (95-98\%) resection of 
malignant gliomas are the insufficient visualization of the tumor boundaries because of its infiltrative growth and the need to preserve functionally significant brain structures. With the traditional removal of the tumor under the guidance of white light microscopy, the maximal level of resection can be reached only in 23$50 \%$ of cases $[9,17]$. These unresolved issues stimulate a search for novel approaches to intraoperative diagnosis of the boundaries of malignant brain tumors.

Currently, there are a number of methods that assist in achieving the maximal degree of resection with a minimal risk of functional complications; among them, intraoperative CT and/or MRI [5, 18-21], ultrasound scanning [22-24], neuro-navigation systems [2527], fluorescent diagnostics [28-36], intraoperative neurophysiological monitoring, awake craniotomy and various combinations of the above. These methods are based on several principles: a) the use of contrast substances accumulating in the tumor vasculature (CT, MRI); b) the detection of metabolic changes in tissues (MR spectroscopy, DVI, fluorescent probes, laser spectroscopy); c) the changes in tissue density (ultrasound diagnosis). The above methods do not include the navigation systems, where the tissue transformation is diagnosed within the preoperative patient examination $[1,37]$. At present, a research into the use of confocal microscopy and optical coherence tomography for intraoperative brain imaging is under way [38-42].

However, each of these approaches has its own limitations; therefore, the current search for new technologies of intraoperative diagnosis of tumor boundaries is important. Our study demonstrates the feasibility of the proposed method based on the measurement of field potentials in a brain tumor and its vicinity.

\section{Conclusion}

In neurosurgery, there is a pressing need to identify the brain tumors boundaries to prevent an accidental damage to vital brain structures during surgery. In the present study, we propose a new diagnostic criterion for determining the glial brain tumors boundaries by recording the field potentials triggered by electrical stimulation. This criterion is unique for neurosurgery, because it is based on the evaluation of the brain tissue function rather than its morphology. The proposed diagnostic system with two mutually arranged electrodes may soon find the intraoperative use, thanks to its high accuracy, which can theoretically reach submillimeter values.

Acknowledgements. We thank Olga V. Tyurikova and Yuliya V. Dembitskaya for their consultation in designing of the experiments, their useful comments, and critical view.

Financial support. The study was supported by the Russian Foundation for Basic Research (project 16-31-
60080 mol_a_dk), the government assignment (projects 17.3335.2017/4.6 and 6.6659.2017/6.7), a grant from the President of the Russian Federation MD-2634.2017.4 and scholarships awarded by the President of the Russian Federation SP-2458.2018.5.

Conflict of interest. The authors declare no conflict of interest.

\section{References}

1. Mahboob S.O., Eljamel M. Intraoperative image-guided surgery in neuro-oncology with specific focus on high-grade gliomas. Future Oncol 2017; 13(26): 2349-2361, https://doi. org/10.2217/fon-2017-0195.

2. Cohen A.L., Colman H. Glioma biology and molecular markers. Cancer Treat Res 2015; 163: 15-30, https://doi. org/10.1007/978-3-319-12048-5_2.

3. Smolin A.V., Bekyashev A.H., Kobyakov G.L., Sharabura T.M., Mufazalov F.F., Kanischeva N.V., Bumagina V.O. First results of the Russian multicenter epidemiology project on the malignant gliomas. Sovremennaya onkologiya 2014; 16(2): 50-55.

4. de Paula L.B., Primo F.L., Tedesco A.C. Nanomedicine associated with photodynamic therapy for glioblastoma treatment. Biophys Rev 2017; 9(5): 761-773, https://doi. org/10.1007/s12551-017-0293-3.

5. Eljamel M.S., Mahboob S.O. The effectiveness and cost-effectiveness of intraoperative imaging in high-grade glioma resection; a comparative review of intraoperative ALA, fluorescein, ultrasound and MRI. Photodiagnosis Photodyn Ther 2016; 16: 35-43, https://doi.org/10.1016/j. pdpdt.2016.07.012.

6. Absalyamova O.V., Anikeeva O.Yu., Golanov A.V., Kobyakov G.L., Konovalov A.N., Kornienko V.N., Krivoshapkin A.L., Loshakov V.A., Olyushin V.E., Potapov A.A., Ryzhova M.V., Tanyashin S.V., Trunin Yu.Yu., Ulitin A.Yu., Shishkina L.V. Klinicheskie rekomendatsii po lecheniyu pervichnykh opukholey tsentralnoy nervnoy sistemy [Clinical guidelines for the treatment of primary central nervous system tumors]. Nizhny Novgorod; 2013.

7. Reitman Z.J., Winkler F., Elia A.E.H. New directions in the treatment of glioblastoma. Semin Neurol 2018; 38(1): 5061, https://doi.org/10.1055/s-0038-1623534.

8. Ulitin A.Yu., Matsko D.E., Olyushin V.E. Neyroepitelialnye opukholi golovnogo mozga [Neuroepithelial brain tumors]. Saint Petersburg: Izd-vo FGBU "RNKHI im. prof. A.L. Polenova"; 2014.

9. Anokhina Yu.E., Gaidar B.V., Martynov B.V., Svistov D.V., Papayan G.V., Grigorievsky D.I. Prognostic significance of surgery volume under fluorescent intraoperative diagnostic applications in patients with malignant brain gliomas. Vestnik Rossijskoj voenno-medicinskoj akademii 2014; 1(45): 19-24.

10. Sanai N., Chang S., Berger M.S. Low-grade gliomas in adults: a review. J Neurosurg 2011; 115(5): 948-965, https:// doi.org/10.3171/2011.7.jns10238.

11. Kuhnt D., Becker A., Ganslandt O., Bauer M., Buchfelder M., Nimsky C. Correlation of the extent of tumor volume resection and patient survival in surgery of glioblastoma multiforme with high-field intraoperative MRI guidance. Neuro Oncol 2011; 13(12): 1339-1348, https://doi. org/10.1093/neuonc/nor133. 
12. Robert S.M., Sontheimer H. Glutamate transporters in the biology of malignant gliomas. Cell Mol Life Sci 2014; 71(10): 1839-1854, https://doi.org/10.1007/s00018-013-1521-z.

13. Khalansky A.S., Kondakova L.I. Transplanted rat glioma 101.8. I. Biological characteristics. Klinicheskaya $i$ eksperimentalnaya morfologiya 2013; 4(8): 63-69.

14. Lebedeva A.V., Dembitskaya Y.V., Pimashkin A.S., Zhuravleva Z.D., Shishkova E.A., Semyanov A.V. The role of energy substrates in astrocyte calcium activity of rat hippocampus in early postnatal ontogenesis. Sovremennye tehnologii $v$ medicine 2015; 7(3): 14-19, https://doi. org/10.17691/stm2015.7.3.02.

15. Lebedeva A., Plata A., Nosova O., Tyurikova O., Semyanov A. Activity-dependent changes in transporter and potassium currents in hippocampal astrocytes. Brain Res Bull 2018; 136: 37-43, https://doi.org/10.1016/j. brainresbull.2017.08.015.

16. Sofroniew M.V., Vinters H.V. Astrocytes: biology and pathology. Acta Neuropathol 2010; 119(1): 7-35, https://doi. org/10.1007/s00401-009-0619-8.

17. Vogelbaum M.A. Does extent of resection of a glioblastoma matter? Clin Neurosurg 2012; 59: 79-81, https:// doi.org/10.1227/neu.0b013e31826b2e75.

18. Li P., Qian R., Niu C., Fu X. Impact of intraoperative MRI-guided resection on resection and survival in patient with gliomas: a meta-analysis. Curr Med Res Opin 2017; 33(4): 621-630, https://doi.org/10.1080/03007995.2016.1275935.

19. Scherer M., Jungk C., Younsi A., Kickingereder P., Müller S., Unterberg A. Factors triggering an additional resection and determining residual tumor volume on intraoperative MRI: analysis from a prospective single-center registry of supratentorial gliomas. Neurosurg Focus 2016; 40(3): E4, https://doi.org/10.3171/2015.11.focus15542.

20. Kubben P.L., Scholtes F., Schijns O.E., Ter LaakPoort M.P., Teernstra O.P., Kessels A.G., van Overbeeke J.J., Martin D.H., van Santbrink $H$. Intraoperative magnetic resonance imaging versus standard neuronavigation for the neurosurgical treatment of glioblastoma: a randomized controlled trial. Surg Neurol Int 2014; 5: 70, https://doi. org/10.4103/2152-7806.132572.

21. Senft C., Bink A., Franz K., Vatter H., Gasser T., Seifert V. Intraoperative MRI guidance and extent of resection in glioma surgery: a randomised, controlled trial. Lancet Oncol 2011; 12(11): 997-1003, https://doi.org/10.1016/s14702045(11)70196-6.

22. Enchev Y., Bozinov O., Miller D., Tirakotai W., Heinze S., Benes L., Bertalanffy H., Sure U. Image-guided ultrasonography for recurrent cystic gliomas. Acta Neurochir (Wien) 2006; 148(10): 1053-1063, https://doi.org/10.1007/ s00701-006-0858-6.

23. Cheng L.G., He W., Zhang H.X., Song Q., Ning B., Li H.Z., He Y., Lin S. Intraoperative contrast enhanced ultrasound evaluates the grade of glioma. Biomed Res Int 2016; 2016: 2643862, https://doi.org/10.1155/2016/2643862.

24. Prada F., Mattei L., Del Bene M., Aiani L., Saini M., Casali C., Filippini A., Legnani F.G., Perin A., Saladino A., Vetrano I.G., Solbiati L., Martegani A., DiMeco F. Intraoperative cerebral glioma characterization with contrast enhanced ultrasound. Biomed Res Int 2014; 2014: 484261, https://doi. org/10.1155/2014/484261.

25. Wirtz C.R., Albert F.K., Schwaderer M., Heuer C., Staubert A., Tronnier V.M., Knauth M., Kunze S. The benefit of neuronavigation for neurosurgery analyzed by its impact on glioblastoma surgery. Neurol Res 2000; 22(4): 354-360, https://doi.org/10.1080/01616412.2000.11740684.

26. Tursynov N., Grigolashvili M., Kauynbekova S., Grigolashvili S. Evaluating the efficacy of neuronavigation in surgical treatment of glial tumors. Georgian Med News 2017; 262: 14-20.

27. Gerard I.J., Kersten-Oertel M., Petrecca K., Sirhan D., Hall J.A., Collins D.L. Brain shift in neuronavigation of brain tumors: a review. Med Image Anal 2017; 35: 403-420, https:// doi.org/10.1016/j.media.2016.08.007.

28. Suero Molina E., Schipmann S., Stummer W. Maximizing safe resections: the roles of 5 -aminolevulinic acid and intraoperative MR imaging in glioma surgery-review of the literature. Neurosurg Rev 2017, https://doi.org/10.1007/ s10143-017-0907-z.

29. Xie Y., Thom M., Ebner M., Wykes V., Desjardins A., Miserocchi A., Ourselin S., McEvoy A.W., Vercauteren T. Widefield spectrally resolved quantitative fluorescence imaging system: toward neurosurgical guidance in glioma resection. $J$ Biomed Opt 2017; 22(11): 1-14, https://doi.org/10.1117/1. jbo.22.11.116006.

30. Eljamel S. 5-ALA fluorescence image guided resection of glioblastoma multiforme: a meta-analysis of the literature. Int J Mol Sci 2015; 16(5): 10443-10456, https://doi.org/10.3390/ ijms160510443.

31. Acerbi F., Cavallo C., Schebesch K.M., Akçakaya M.O., de Laurentis C., Hamamcioglu M.K., Broggi M., Brawanski A., Falco J., Cordella R., Ferroli P., Kiris T., Höhne J. Fluoresceinguided resection of intramedullary spinal cord tumors: results from a preliminary, multicentric, retrospective study. World Neurosurg 2017; 108: 603-609, https://doi.org/10.1016/j. wneu.2017.09.061.

32. Acerbi F., Broggi M., Eoli M., Anghileri E., Cavallo C., Boffano C., Cordella R., Cuppini L., Pollo B., Schiariti M., Visintini S., Orsi C., La Corte E., Broggi G., Ferroli P. Is fluorescein-guided technique able to help in resection of highgrade gliomas? Neurosurg Focus 2014; 36(2): E5, https://doi. org/10.3171/2013.11.focus13487.

33. Barone D.G., Lawrie T.A., Hart M.G. Image guided surgery for the resection of brain tumours. Cochrane Database Syst Rev 2014; 1: CD009685, https://doi. org/10.1002/14651858.cd009685.pub2.

34. Li Y., Rey-Dios R., Roberts D.W., Valdés P.A., Cohen-Gadol A.A. Intraoperative fluorescence-guided resection of high-grade gliomas: a comparison of the present techniques and evolution of future strategies. World Neurosurg 2014; 82(1-2): 175-185, https://doi.org/10.1016/j. wneu.2013.06.014.

35. Jenkinson M.D., Barone D.G., Bryant A., Vale L., Bulbeck H., Lawrie T.A., Hart M.G., Watts C. Intraoperative imaging technology to maximise extent of resection for glioma. Cochrane Database Syst Rev 2018; 1: CD012788, https://doi. org/10.1002/14651858.cd012788.pub2.

36. Goriainov S.A., Potapov A.A., Pitskhelauri D.I., Kobiakov G.L., Okhlopkov V.A., Gavrilov A.G., Shurkhai V.A., Zhukov V.Iu., Shishkina L.V., Loshchenov V.B., Savel'eva T.A., Kuz'min S.G., Chumakova A.P., Spallone A. Intraoperative fluorescence diagnostics upon recurrent operations for brain gliomas. Voprosy neyrokhirurgii im. N.N. Burdenko 2014; 78(2): 22-31.

37. Tyurikova O., Dembitskaya Y., Yashin K., Mishchenko M., Vedunova M., Medyanik I., Kazantsev V. Perspectives in intraoperative diagnostics of human gliomas. 
Comput Math Methods Med 2015; 2015: 1-9, https://doi. org/10.1155/2015/479014.

38. Banc A., Stan C., Florian I.S. Optical coherence tomography as a marker of vision in children with optic pathway gliomas. Childs Nerv Syst 2018; 34(1): 51-60, https:// doi.org/10.1007/s00381-017-3578-8.

39. Garzon-Muvdi T., Kut C., Li X., Chaichana K.L. Intraoperative imaging techniques for glioma surgery. Future Oncol 2017; 13(19): 1731-1745, https://doi.org/10.2217/fon2017-0092.

40. Gempt J., Bette S., Ryang Y.M., Buchmann N., Peschke P., Pyka T., Wester H.J., Förster S., Meyer B., Ringel F. 18F-fluoro-ethyl-tyrosine positron emission tomography for grading and estimation of prognosis in patients with intracranial gliomas. Eur J Radiol 2015; 84(5): 955-962, https://doi. org/10.1016/j.ejrad.2015.01.022.

41. Zehri A.H., Ramey W., Georges J.F., Mooney M.A., Martirosyan N.L., Preul M.C., Nakaji P. Neurosurgical confocal endomicroscopy: a review of contrast agents, confocal systems, and future imaging modalities. Surg Neurol Int 2014; 5(1): 60, https://doi.org/10.4103/2152-7806.131638.

42. Kiseleva E.B., Yashin K.S., Moiseev A.A., Snopova L.B., Gelikonov G.V., Medyanik I.A., Kravets L.Ya., Karyakin N.N., Vitkin I.A., Gladkova N.D. Quantitative cross-polarization optical coherence tomography detection of infiltrative tumor margin in a rat glioma model: a pilot study. Sovremennye tehnologii v medicine 2018; 10(1): 6, https://doi.org/10.17691/ stm2018.10.1.01. 